\title{
FAKTOR-FAKTOR YANG BERHUBUNGAN DENGAN PEMAKAIAN KONTRASEPSI IMPLANT PADA IBU PASANGAN USIA SUBUR (PUS) D PUSKESMAS AEK NAULI KEC.SIANTAR SELATAN KOTA PEMATANG SIANTAR TAHUN 2017.
}

\section{The Related Factors of Implant Contraception Usage To The Fertile Age Couple (PUS) In Aek Nauli Community Health Center Siantar South City At 2017}

\author{
Ramadhani Syafitri ${ }^{1}$, Rapida Saragih ${ }^{2}$ \\ ${ }^{1 *}$ Dosen D4 Kebidanan InstitutKesehatan Helvetia, \\ ${ }^{2}$ Dosen D4 Kebidanan Institut Kesehatan Helvetia \\ Email : ramadhanisyafitri@ helvetia.ac.id
}

\begin{abstract}
ABSTRAK
Tingkat kematian, terutama kematian bayi dan anak, erat kaitannya dengan masalah kualitas penduduk. Untuk meningkatkan kualitas penduduk usaha yang dapat menaikkan tingkat kesehatan, pengetahuan dan sikap serta prilaku masyarakat untuk hidup sehat terus ditingkatkan. Upaya langsung untuk menurunkan kelahiran dilaksanakan melalui program keluarga berencana, yaitu dengan mengajak pasangan usia subur (PUS) agar memakai kontrasepsi. Sedangkan jenis alat kontrasepsi yang dipakai ditingkatkan kepada yang lebih efektif, Tujuan dari penelitian ini adalah mengetahui faktor-faktor yang berhubungan dengan pemakaian kontrasepsi implant pada ibu pasangan usia subur (PUS) di Puskesmas Aek Nauli Kec.Siantar Selatan Kota Pematang Siantar Tahun 2017.Jenis penelitian ini adalah survey analitik yang bersifat cross sectional dengan pengolahan data menggunakan analisis univariat dan analisis bivariat, sampel sebanyak 30 orang.Hasil penelitian diperoleh faktor-faktor yang berhubungan dengan pemakaian kontrasepsi implant pada ibu pasangan usia subur (PUS) di Puskesmas Aek Nauli Kec.Siantar Selatan Kota Pematang Siantar yaitu ditinjau dari pendidikan dasar 6 orang (20.0\%), Menengah 11 (36.7\%), tinggi 13 (43.3\%), Faktor pengetahuan baik 3 orang $(10.0 \%)$, cukup 1 orang (36.7\%), kurang 16 orang (53.3\%), dari faktor dukungan suami yang mendukung 9 orang (30.0\%), tidak mendukung 21 orang (70.0\%). Kesimpulan dari penelitian ini adalah ada hubungan yang bermakna antara pendidikan, pengetahuan, dan dukungan suami dengan pemakaian kontrasepsi implant, bagi ibu pasangan usia subur (PUS) .
\end{abstract}

Kata Kunci: Kontrasepsi, Implant, Pendidikan, Pengetahuan, Dukungan

\section{ABSTRACT}

Death rates, especially infant and child mortality, are closely related to population quality problems. To improve the quality of business population that can raise the level of health, knowledge and attitudes and behavior of people for healthy living continues to be improved. Direct efforts to reduce births are done through family planning programs, by inviting the fertile couples (EFA) to use contraception. While the type of contraceptive tool used is improved to be more effective, The purpose of this study is to know the factors associated with the use of contraceptive implant in the mother of the fertile age couple (PUS) at AekNauli Public Health Center Kec.Siantar Selatan PematangSiantar City in 2017.The type of this research is analytical survey that is cross sectional with data processing using univariate and bivariate analysis, sample of 30 peopleThe result of research showed that factors related to the use of contraception implant at mother of fertile age couple (PUS) at AekNauli Health Center Kec.Siantar Selatan PematangSiantar City is observed from basic education 6 people (20.0\%), Medium 11 (36.7\%), high 13 (43.3\%), knowledge factor of 3 people (10.0\%), enough 1 person (36.7\%), less 16 people (53.3\%), of husband support factor supporting 9 people (30.0\%), did not support 21 people (70.0\%).The conclusion of this study is that there is a significant relationship between education, knowledge, and husband support with implant contraceptive use, for mothers of fertile age couples are expected to use safe contraceptives and effectively prevent from unwanted pregnancies, one of which is using long term contraception the length of the implant is more practical and effective use of the mother

Keywords: Contraception, implant, education, knowledge, support 


\section{PENDAHULUAN}

Pertumbuhan penduduk adalah perubahan jumlah penduduk disuatu wilayah tertentu pada waktu tertentu dibandingkan waktu sebelumnya. Indikator tingkat pertumbuhan sangat berguna untuk memprediksi jumlah penduduk disuatu wilayah atau negara dimasa yang akan datang. Dengan diketahuinya jumlah penduduk yang akan datang, diketahui pula kebutuhan dasar penduduk ini, tidak hanya dibidang sosial dan ekonomi tetapi juga dibidang politik ${ }^{1}$

Tingkat kematian, terutama kematian bayi dan anak, erat kaitannya dengan masalah kualitas penduduk. Untuk meningkatkan kualitas penduduk usaha yang dapat menaikkan tingkat kesehatan, pengetahuan dan sikap serta prilaku masyarakat untuk hidup sehat terus ditingkatkan. Upaya langsung untuk menurunkan kelahiran dilaksanakan melalui program keluarga berencana, yaitu dengan mengajak pasangan usia subur (PUS) agar memakai kontrasepsi. Sedangkan jenis alat kontrasepsi yang dipakai ditingkatkan kepada yang lebih efektif ${ }^{2}$

Menurut WHO (World Health Organisation)

: Keluarga berencana adalah tindakan yang membantu pasangan suami istri untuk menghindari kehamilan yang tidak diinginkan, mengatur interval diantara kehamilan, mengontrol waktu saat kelahiran dalam hubungan dengan umur suami istri serta menentukan jumlah anak dalam keluarga. ${ }^{3}$

Dari data yang diperoleh dari Data Dan Informasi Kesehatan dan Profil Kesehatan Indonesia Tahun 2016 persentase akseptor KB aktif menurut metode kontrasepsi dan provinsi tahun 2016, jumlah seluruh pasangan usia subur di Indonesia tahun 2016 sebanyak 48.536 .690 yang menggunakan kontarsepsi 36.306 .690 $(74.80 \%)$. Metode kontrasepsi kondom 1.171 .509 (3,23 \%), Pil 8.280.823 (22,81\%), Suntik 17.414.144 (47,96\%), IUD 3.852.561 (10,61\%), Implant 4.067.699 (11,20\%), MOW 1.285.991 (3,54\%), MOP $233.935(0,64 \%){ }^{7}$

Pengetahuan tentang kebutuhan tubuh akan zat gizi berpengaruh terhadap jumlah dan jenis pangan yang dikonsumsi. Dalam kehidupan masyarakat sehari-hari, sering terlihat keluarga yang sesungguhnya berpenghasilan cukup, tetapi makanan yang dihidangkan seadanya saja. Keadaan ini menunjukkan ketidaktahuan akan faedah makanan bagi kesehatan tubuh, merupakan sebab buruknya mutu gizi makanan keluarga. ${ }^{6}$
Sikap ibu juga merupakan salah satu faktor yang mempengaruhi terjadinya gizi buruk. Sikap ibu yang kurang baik terhadap pemberian makanan berpengaruh terhadap pola konsumsi anak, sehingga menghasilkan anak yang kurang gizi. $^{7}$

Dari laporan BKKBN (Badan Kependudukan dan Keluarga Berencana) provinsi Sumatra Utara pencapaian peserta keluarga berencana (KB) aktif bulan April 2016 yang berhasil dibina sebanyak 1.472 .990 dari seluruh pasangan usia subur yang mencapai 2.210 .958 PUS. Realisasi perserta KB aktif menggunakan kontrasepsi suntik $453.500(30,79 \%)$ orang, pil $437.322(29,69 \%)$ orang, IUD $151.492(10,28 \%)$ orang, Metode Operatif Wanita (MOP) 108 $(0,39 \%)$.

Dari laporan Badan Pusat Statistik Kota Pematang Siantar diperoleh pada tahun 2015 akseptor KB sebanyak 27.746 orang. Pengguna IUD 3210 orang $(11,6 \%)$, suntik 7651 orang $(27,6 \%)$, pil 5868 orang $(21,1 \%)$, MOW 3995 orang $(14,4 \%)$, MOP 185 orang $(0,7 \%)$, Implant 3916 orang $(14,1 \%)$, dan kondom 2921 orang $(10,5 \%)$. Pada Kecamatan Siantar Selatan jumlah akseptor KB 1827 orang. IUD 242 orang (12,9 $\%)$, suntik 480 orang $(25,6 \%)$, pil 316 orang $(16,9 \%)$, MOW 443 orang $(23,7 \%)$, MOP tidak ada (0\%), implant 216 orang $(11,5 \%)$, dan kondom 176 orang $(9,4 \%){ }^{9}$

Berdasarkan data laporan bulanan yang diperoleh dari Puskesmas Aek Nauli Kec. Siantar Selatan Kota Pematang Siantar pada bulan Mei 2017 terdapat 431 akseptor KB aktif. Pengguna suntik 228 orang $(52,9 \%)$, Pil 57 orang $(13,2 \%)$, IUD 41 orang $(9,6 \%)$,Implant 30 orang (7\%), MOW 65 orang (15\%), MOP tidak ada $(0 \%)$, kondom 10 orang $(2,3 \%)$. Dan dari survey awal dilakukan wawancara kepada 10 orang Ibu Pasangan Usia Subur (PUS), dari 10 orang tersebut 8 orang tidak mengunakan kontrasepsi non implant, alasan mereka tidak menggunakan implant 5 orang mengatakan tidak terlalu mengetahui tentang implant dan sisangya mengatakan takut saat pemasangan implant.

Sehubungan dengan rendahnya penggunaan kontrasepsi implant dibandingkan dengan kontrasepsi hormonal lainnya dan upaya untuk meningkatkan kesertaan KB Mertode Kontrasepsi Jangka Panjang (MKJP) bagi penerima layanan (demand) maupun aspek pemberi layanan (supply).Oleh sebab itu peneliti ingin mengetahui Faktor - Faktor Yang Berhubungan Dengan Pemakaian Kontrasepsi 
Implant Pada Ibu Pasanga Usia Subur (PUS) di Puskesma Aek Nauli Kec. Siantar Selatan Kota Pematang Siantar Tahun 2017.

\section{METODE PENELITIAN}

Penelitian ini dilakukan di Puskesmas Aek Nauli Kec.Siantar Selatan Kota Pematang Siantar pada bulan September 2017 dengan populasi penelitian seluruh pengguna kontrasepsi implant di Puskesmas Aek Nauli Kec.Siantar Selatan Kota Pematang Siantar dengan jumlah sebanyak 30 orang. Penetapan jumlah sampel dalam penelitian ini menggunakan Total Sampling sebanyak 30 orang ibu.

Desain penelitian ini menggunakan metode Survei Analitik dengan pendekatan cross sectional survey.dengan variable bebas yaitu factor umur, pendidikan, paritas, pengetahuan dan dukungan suami dan variable terikat adalah pemakaian implant. Metode pengumpulan data dilakukan dengan menyebarkan kuisioner kepada responden.

Data yang dikumpulkan, diolah dengan komputer.Analisa data yang dilakukan adalah analisis univariat dan analisis bivariat.Analisis dilakukan untuk melihat hubungan masingmasing variable bebas dengan variable terikat. Untuk membuktikan adanya hubungan yang signifikan antara variable bebas dan variable terikat digunakan analisis Chi-square, pada batas kemaknaan perhitungan statistic $p$ value $(0,05)$.

\section{HASIL}

Setelah dilakukan penelitian, maka diperoleh hasil sebagai berikut :

Tabel 1. Distribusi Frekuensi Umur Pasangan Usia Subur (PUS) Dengan Pemakaian Kontrasepsi Implant Di Puskesmas Aek Nauli Kec.Siantar Selatan Kota Pematang Siantar Tahun 2017.

\begin{tabular}{ccccccccc}
\hline \multirow{2}{*}{$\begin{array}{c}\text { N } \\
\mathbf{0}\end{array}$} & \multirow{6}{c}{ Umur } & \multicolumn{6}{c}{ Penggunaan Implant } & \multirow{2}{*}{$\begin{array}{c}\text { Signifika } \\
\text { n }\end{array}$} \\
\cline { 3 - 8 } & & $\mathbf{5}$ Tahun & $\mathbf{\%}$ & $\mathbf{f}$ & $\mathbf{\%}$ & $\mathbf{f}$ & $\mathbf{\%}$ & $\mathbf{0 . 0 9 4}$ \\
\hline $\mathbf{1}$ & $20-35$ Tahun & 5 & 16.7 & 13 & 43.3 & 18 & 60.0 & \\
\hline $\mathbf{2}$ & $>35$ Tahun & 7 & 23.3 & 5 & 16.7 & 12 & 40.0 & \\
\hline & Total & $\mathbf{1 2}$ & $\mathbf{4 0 . 0}$ & $\mathbf{1 8}$ & $\mathbf{6 0 . 0}$ & $\mathbf{3 0}$ & $\mathbf{1 0 0}$ & \\
\hline
\end{tabular}

Berdasarkan tabel 1 berdasarkan uji statistik chi-square pada tingkat kepercayaan $95 \%$ dengan $\alpha=0.05$ diperoleh $\mathrm{p}=0.094$, maka $\mathrm{p}(0.094)>\alpha$ (0.05). Dengan demikian diperoleh hasil bahwa umur responden tidak memiliki hubungan yang signifikan dengan penggunaan kontrasepsi implant pada ibu pasangan usia subur (pus) di Puskesmas Aek Nauli Kec.Siantar Selatan Kota Pematang Siantar Tahun 2017.

Tabel 2. Distribusi Frekuensi Pendidikan Pasangan Usia Subur (PUS) Dengan Pemakaian Kontrasepsi Implant Di Puskesmas Aek Nauli Kec.Siantar Selatan Kota Pematang Siantar Tahun 2017

\begin{tabular}{|c|c|c|c|c|c|c|c|c|}
\hline \multirow{3}{*}{$\begin{array}{c}\mathbf{N} \\
\mathbf{0}\end{array}$} & \multirow{3}{*}{ Pendidikan } & \multicolumn{6}{|c|}{ Penggunaan Implant } & \multirow{3}{*}{$\begin{array}{c}\text { Signifika } \\
n\end{array}$} \\
\hline & & \multicolumn{2}{|c|}{$<5$ Tahun } & \multicolumn{2}{|c|}{$>5$ Tahun } & \multicolumn{2}{|c|}{ Jumlah } & \\
\hline & & $\mathbf{f}$ & $\%$ & f & $\%$ & $\mathbf{f}$ & $\%$ & \\
\hline 1 & Dasar & 1 & 3.3 & 5 & 16.7 & 6 & $\begin{array}{c}20 . \\
0\end{array}$ & \\
\hline 2 & Menengah & 2 & 6.7 & 9 & 30.0 & 11 & $\begin{array}{c}36 . \\
7\end{array}$ & 0.017 \\
\hline 3 & Tinggi & 9 & 30.0 & 4 & 13.3 & 13 & $\begin{array}{c}43 . \\
3\end{array}$ & \\
\hline & Total & 12 & 40.0 & 18 & 60.0 & 30 & 100 & \\
\hline
\end{tabular}

Berdasarkan tabel 2 berdasarkan uji statisti chi- faktor pendidikan memiliki hubungan yang square pada tingkat kepercayaan $95 \%$ dengan $\alpha$ signifikan dengan pemakaian kontrasepsi $=0.05$ diperoleh $\mathrm{p}=0.017$. Maka $\mathrm{p}(0.017)<\alpha \quad$ implant pada ibu pasangan usia subur (PUS) di

(0.05). Dengan demikian diperoleh hasil bahwa 
Puskesmas Aek Nauli Kec.Siantar Selatan Kota Pematang Siantar tahun 2017.

Tabel 3. Distribusi Frekuensi Paritas Pasangan Usia Subur (PUS) Dengan Pemakaian Kontrasepsi Implant Di Puskesmas Aek Nauli Kec.Siantar Selatan Kota Pematang Siantar Tahun 2017

\begin{tabular}{|c|c|c|c|c|c|c|c|c|}
\hline \multirow{3}{*}{$\begin{array}{l}\mathbf{N} \\
\mathbf{0}\end{array}$} & \multirow{3}{*}{ Paritas } & \multicolumn{6}{|c|}{ Penggunaan Implant } & \multirow{3}{*}{ Signifikan } \\
\hline & & \multicolumn{2}{|c|}{$<5$ Tahun } & \multicolumn{2}{|c|}{$>5$ Tahun } & \multicolumn{2}{|c|}{ Jumlah } & \\
\hline & & $\mathbf{f}$ & $\%$ & f & $\%$ & f & $\%$ & \\
\hline 1 & Primipara & 4 & $\begin{array}{c}13 . \\
3\end{array}$ & 2 & 6.7 & 6 & $\begin{array}{c}20 . \\
0\end{array}$ & \multirow{4}{*}{0.282} \\
\hline 2 & Multipara & 5 & $\begin{array}{c}16 . \\
7\end{array}$ & 8 & $\begin{array}{c}26 . \\
7\end{array}$ & 11 & $\begin{array}{c}36 . \\
7\end{array}$ & \\
\hline \multirow[t]{2}{*}{3} & $\begin{array}{l}\text { Grande } \\
\text { Multipara }\end{array}$ & 3 & $\begin{array}{c}10 . \\
0\end{array}$ & 8 & $\begin{array}{c}26 . \\
7\end{array}$ & 11 & $\begin{array}{c}36 . \\
7\end{array}$ & \\
\hline & Total & 12 & $\begin{array}{c}40 . \\
0\end{array}$ & 18 & $\begin{array}{c}60 . \\
0\end{array}$ & 30 & 100 & \\
\hline
\end{tabular}

Berdasarkan tabel 9 berdasarkan uji statisti chisquare pada tingkat kepercayaan $95 \%$ dengan $\alpha$ $=0.05$ diperoleh $\mathrm{p}=0.282$. Maka $\mathrm{p}(0.282)>\alpha$ signifikan dengan pemakaian kontrasepsi implant pada ibu pasangan usia subur (pus) di Puskesmas Aek Nauli Kec.Siantar Selatan Kota (0.05). Dengan demikian diperoleh hasil bahwa faktor paritas tidak memiliki hubungan yang

Pematang Siantar tahun 2017.

Tabel 4. Distribusi Frekuensi Pengetahuan Pasangan Usia Subur (PUS) Dengan Pemakaian Kontrasepsi Implant Di Puskesmas Aek Nauli Kec.Siantar Selatan Kota Pematang Siantar Tahun 2017

\begin{tabular}{|c|c|c|c|c|c|c|c|c|}
\hline \multirow{3}{*}{$\begin{array}{l}\mathbf{N} \\
\mathbf{0}\end{array}$} & \multirow{3}{*}{ Pengetahuan } & \multicolumn{6}{|c|}{ Penggunaan Implant } & \multirow{3}{*}{ Signifikan } \\
\hline & & \multicolumn{2}{|c|}{$<5$ Tahun } & \multicolumn{2}{|c|}{$>5$ Tahun } & \multicolumn{2}{|c|}{ Jumlah } & \\
\hline & & $\mathbf{f}$ & $\%$ & $\mathbf{f}$ & $\%$ & $\mathbf{f}$ & $\%$ & \\
\hline 1 & Baik & 3 & $\begin{array}{c}10 . \\
0\end{array}$ & 0 & 0 & 3 & $\begin{array}{c}10 . \\
0\end{array}$ & \multirow{4}{*}{0.014} \\
\hline 2 & Cukup & 6 & $\begin{array}{c}20 . \\
0\end{array}$ & 5 & $\begin{array}{c}16 . \\
7\end{array}$ & 11 & $\begin{array}{c}36 . \\
7\end{array}$ & \\
\hline \multirow[t]{2}{*}{3} & Kurang & 3 & $\begin{array}{c}10 . \\
0\end{array}$ & 13 & $\begin{array}{c}43 . \\
3\end{array}$ & 16 & $\begin{array}{c}53 . \\
3\end{array}$ & \\
\hline & Total & 12 & $\begin{array}{c}40 . \\
0\end{array}$ & 18 & $\begin{array}{c}60 . \\
0\end{array}$ & 30 & 100 & \\
\hline
\end{tabular}

Berdasarkan tabel 4 berdasarkan uji statisti chisquare pada tingkat kepercayaan $95 \%$ dengan $\alpha$ $=0.05$ diperoleh $\mathrm{p}=0.014$. Maka $\mathrm{p}(0.014)<\alpha$ (0.05). Dengan demikian diperoleh hasil bahwa faktor pengetahuan memiliki hubungan yang

signifikan dengan pemakaian kontrasepsi implant pada ibu pasangan usia subur (PUS) di Puskesmas Aek Nauli Kec.Siantar Selatan Kota Pematang Siantar tahun 2017.

Tabel 5. Distribusi Frekuensi Dukungan Suami Pasangan Usia Subur (PUS) Dengan Pemakaian Kontrasepsi Implant Di Puskesmas Aek Nauli Kec.Siantar Selatan Kota Pematang Siantar Tahun 2017

\begin{tabular}{|c|c|c|c|c|c|c|c|c|}
\hline \multirow{3}{*}{$\begin{array}{l}\mathbf{N} \\
\mathbf{0}\end{array}$} & \multirow{3}{*}{ Dukungan Suami } & \multicolumn{6}{|c|}{ Penggunaan Implant } & \multirow{3}{*}{$\begin{array}{c}\text { Signifika } \\
\text { n }\end{array}$} \\
\hline & & \multicolumn{2}{|c|}{$\begin{array}{c}<5 \\
\text { Tahun }\end{array}$} & \multicolumn{2}{|c|}{$>5$ Tahun } & \multicolumn{2}{|c|}{$\begin{array}{c}\text { Jumla } \\
\mathbf{h}\end{array}$} & \\
\hline & & $\mathbf{f}$ & $\%$ & $\mathbf{f}$ & $\%$ & $\mathbf{f}$ & $\%$ & \\
\hline 1 & Mendukung & 6 & $\begin{array}{c}20 \\
.0\end{array}$ & 3 & $\begin{array}{c}10 . \\
0\end{array}$ & 9 & $\begin{array}{c}30 \\
.0\end{array}$ & \multirow[b]{2}{*}{0.051} \\
\hline 2 & Tidak Medukung & 6 & $\begin{array}{l}20 \\
.0\end{array}$ & 15 & $\begin{array}{c}50 . \\
0\end{array}$ & $\begin{array}{l}2 \\
1 \\
\end{array}$ & $\begin{array}{l}70 \\
.0\end{array}$ & \\
\hline & Total & 12 & $\begin{array}{r}40 \\
.0\end{array}$ & 18 & $\begin{array}{c}60 . \\
0\end{array}$ & $\begin{array}{l}3 \\
\mathbf{0}\end{array}$ & $\begin{array}{c}10 \\
0 \\
\end{array}$ & \\
\hline
\end{tabular}


Berdasarkan tabel 5 berdasarkan uji statisti chi-square pada tingkat kepercayaan $95 \%$ dengan $\alpha=0.05$ diperoleh $\mathrm{p}=0.051$. Maka $\mathrm{p}(0.051) \leq \alpha$ (0.05). Dengan demikian diperoleh hasil bahwa faktor dukungan suami memiliki hubungan yang signifikan dengan pemakaian kontrasepsi implant pada ibu pasangan usia subur (pus) di Puskesmas Aek Nauli Kec.Siantar Selatan Kota Pematang Siantar tahun 2017.

\section{Hubungan Faktor Usia Dengan Pemakaian Kontrasepsi Implant}

Ditinjau dari faktor umur, hasil penelitian menunjukkan bahwa dari 30 responden penelitian, 18 orang $(60 \%)$ berumur 20-35 tahun, dan 12 orang (40\%) berumur $>35$ tahun, dan tidak ada (0\%) yang berusia $<20$ tahun. Dengan demikian, mayoritas responden berumur 20-35 tahun sebanyak orang (60\%) dan minoritas usia $<20$ tahun sebanyak 0 orang $(0 \%)$.

Hasil penelitian menunjukkan ibu pasangan usia subur (PUS) dengan umur $>20-$ 35 tahun yang menggunakan implant sejumlah 18 orang $(60 \%)$, ini sejalan dengan pendapat Hartanto (2004) pelayanan kontrasepsi diupayakan untuk menurunkan angka kelahiran yang bermakna. Guna mencapai tujuan tersebut maka ditempuh kebijaksanaan mengkategorikan tiga fase untuk mencapai. Penelitian ini sejalan dengan penelitian yang dilakukanPutri yang berjudul Beberapa faktor yang berhubungan dengan pemakaian metode kontrasepsi implant di desa Jimbaran Kecamatan Bandungan Kabupaten Semarang tahun 2014, berdasarkan uji Chi Square didapat nilai Chi-Square sebesar 0,355 dengan $p$-value 0,552 . Oleh karena $p$ value $=0,552>\alpha(0,05)$, disimpulkan bahwa tidak ada hubungan yang signifikan antara umur dengan pemakaian kontrasepsi implant pada WUS di di Desa Jimbaran, Kec. Bandungan, Kab. Semarang tahun 2014. ${ }^{19}$

Menurut asumsi peneliti ibu pasangan usia subur kelompok usia >20-35 tahun adalahkelompokusia yang tepat menggunakan kontrasepsi implant untuk mengatur jarak kehamilan dan untuk mengakhiri kehamilan. Pada kelompok usia <20 tahun belum ada yang menggunakan kontrasepsi implant dapat disebabkan oleh kemungkinan lain seperti pengalaman yang kurang dan pengetahuan yang kurang tentang kontrasepsi implant.

\section{Hubungan Faktor Pendidikan Dengan Pemakaian Kontrasepsi Implant}

Ditinjau dari faktor pendidikan, hasil penelitian menunjukkan dari 30 responden 6 orang $(0.0 \%)$ berpendidikan dasar, 11 orang (36.7\%) berpendidikan menengah, dan 13 orang (43.3\%) berpendidikan tinggi. Dengan demikian mayaoritas responden berpendidikan tinggi sebanyak 13 orang (43.3\%) dan minoritas dengan pendidikan dasar sebanyak 6 orang $(20.0 \%)$.

Berdasarkan uji statisti chi-square pada tingkat kepercayaan 95\% dengan $\alpha=0.05$ diperoleh $\mathrm{p}$ $=0.017$. Maka $\mathrm{p}(0.017)<\alpha(0.05)$. Dengan demikian diperoleh hasil bahwa faktor pendidikan memiliki hubungan yang signifikan dengan pemakaian kontrasepsi implant pada ibu pasangan usia subur (PUS) di Puskesmas Aek Nauli Kec.Siantar Selatan Kota Pematang Siantar tahun 2017.

Penelitian ini sejalan dengan penelitian yang dilakukan Susanti yang berjudul Faktorfaktor yang berhubungan dengan minat ibu terhadap penggunaan alat kontrasepsi implant di Puskesmas Ome Kota Tidore Kepulauan tahun 2015, dari penelitian diperoleh hasil uji chi-square nilai p value 0.011 ini berarti uji statistik terdapat hubungan yang bermakna antara pendidikan dengan pemilihan metode kontrasepsi implant di wilayah kerja puskesmas.

Menurut asumsi peneliti, pendidikan memiliki pengaruh yang besar dalam pengambilan keputusan dalam pemakaian kontrasepsi implant. Karna semakin tinggi pendidikan ibu maka semakin baik pengetahuan yang ibu miliki dan rasa ingin tahu yang tinggi tentang kontrasepsi implant.

\section{Hubungan Faktor Paritas Dengan Pemakaian Kontrasepsi Implant}

Ditinjau dari faktor paritas, hasil penelitian menunjukkan dari 30 responden 6 orang (20\%) paritas primipara, 13 orang $(43.3 \%)$ paritas multipara, dan 11 orang (36.7\%) paritas grande multipara. Dengan demikian mayoritas responden dengan paritas multipara sebanyak 13 orang (43.3\%) dan minoritas dengan paritas primipara sebanyak 6 orang $(20 \%)$.

Berdasarkan uji statisti chi-square pada tingkat kepercayaan 95\% dengan $\alpha=0.05$ diperoleh $p=0.282$. Maka $p(0.282)>\alpha(0.05)$. Dengan demikian diperoleh hasil bahwa faktor paritas tidak memiliki hubungan yang 
signifikan dengan pemakaian kontrasepsi implant pada ibu pasangan usia subur (PUS) di Puskesmas Aek Nauli Kec.Siantar Selatan Kota Pematang Siantar tahun 2017.

Penelitian ini sejalan dengan penelitian yang dilakukan Anita yang berjudul faktorfaktor yang berhubungan dengan pemilihan kontrasepsi pasangan usia subur di Puskesmas Damau Kabupaten Talaud tahun 2014, dari hasil analisis statistik dengan menggunakan uji chi-square nilai $\mathrm{p}=0.726(\mathrm{p}>0.05)$ artinya tidak ada hubungan yang signifikan antara paritas dengan pemilihan kontrasepsi.

Menurut asumsi peneliti, jumlah paritas multipata dan grande multipara merupakan jumlah paritas yang sangat tepat untuk menggunakan kontrasepsi implant, dengan jumlah paritas yang sudah tinggi juga akan meningkatkan resiko tinggi pada ibu jika terus hamil dan melahirkan. Ibu harus diberikan kesempatan untuk beristirahat dari prose kehamilan dan melahirkan, ibu harus merawat diri dan fokus merawat anak-anaknya, namun pada kenyataannya banyak ibu pasangan usia subur yang memiliki paritas tinggi dan ini bertentangan dengan motto keluarga berencana saat ini yaitu 2 anak lebih baik, sehingga diharapkan dapat tercipta keluarga yang berkualitas.

\section{Hubungan Faktor Pengetahuan Dengan Pemakaian Kontrsepsi Implant}

Ditinjau dari faktor pengetahuan, hasil penelitian menunjukkan dari 30 responden sebanyak 3 orang $(10.0 \%)$ berpengetahuan baik, sebanyak 11 orang $(36.7 \%)$ berpengetahuan cukup, dan sebanyak 16 orang (53.3\%) berpengetahuan kurang. Dengan demikian mayoritas responden sebanyak 16 orang (53.3\%) berpengetahuan kurang dan minoritas berpengetahuan baik sebanyak 3 orang $(10.0 \%)$.

Berdasarkan uji statisti chi-square pada tingkat kepercayaan 95\% dengan $\alpha=0.05$ diperoleh $\mathrm{p}=0.014$. Maka $\mathrm{p}(0.014)<\alpha(0.05)$. Dengan demikian diperoleh hasil bahwa faktor pengetahuan memiliki hubungan yang signifikan dengan pemakaian kontrasepsi implant pada ibu pasangan usia subur (pus) di Puskesmas Aek Nauli Kec.Siantar Selatan Kota Pematang Siantar tahun 2017.

Pada tahap terakhir pembentukan pengetahuan inilah responden yang mengetahui tentang implant, terutama keuntungan implant, akan lebih memilih menggunakan implant. Hasil tersebut didukung oleh Notoadmodjo
(2010) bahwa tanpa pengetahuan seseorang tidak mempunyai dasar untuk mengambil keputusan dan menentukan tindakan terhadap masalah yang dihadapi. Pengetahuan atau kognitif merupakan domain yang sangat penting dalam bentuk tindakan seseorang (over behavior ), karena dari pengalaman dan penelitian terbukti bahwa perilaku yang didasari oleh pengetahuan akan lebih langgeng dari pada perilaku yang tidak didasari oleh pegetahuan.

Penelitian ini sejalan dengan penelitian yang dilakukan Putri yang berjudul Beberapa faktor yang berhubungan dengan pemakaian metode kontrasepsi implant di desa JimbaranKecamatan Bandungan Kabupaten Semarang tahun 2014.Berdasarkan uji Chi Square didapat nilai Chi Square sebesar 11,971 dengan $\mathrm{p}$-value 0,003 . Oleh karena $\mathrm{p}$-value $=$ $0,003<\alpha(0,05)$, di simpulkan bahwa ada hubungan yang signifikan antara pengetahuan dengan pemakaian kontrasepsi implant pada WUS di Desa JimbaranKec. Bandungan, Kab.Semarang. ${ }^{19}$

Menurut asumsi peneliti, dari penelitian diperoleh mayoritas responden berpengetahuan cukup, pengetahuan yang baik tentang implant sangatlah berpengaruh besar dalam menentukan keputusan dalam penggunaan implant sebagai kontrasepsi ibu, namun tidak cukup hanya pengetahuan saja ibu jugaharusmendapat dukungan yang positif dari keluarga dalam penggunaan kontrasepsi implant karna pengetahuan yang baik tentang implant juga akan meningkatkan ketakutan ibu dalam menggunakan implant.

\section{Hubungan Faktor Dukungan Suami Dengan Pemakaian Kontrasepsi Implant}

Ditinjau dari faktor dukungan suami, hasil penelitian menunjukkan dari 30 responden sebanyak 9 orang (30.0\%) memperoleh dukungan dari suami dan 21 orang $(70 \%)$ tidak memperoleh dukungan dari suami. Dengan demikian mayoritas responden tidak memperoleh dukungan suami sebnayak 21 orang (70\%) dan minoritas memperoleh dukungan suami sebanyak 9 orang (30.0\%).

Berdasarkan uji statisti chi-square pada tingkat kepercayaan 95\% dengan $\alpha=0.05$ diperoleh $\mathrm{p}=0.051$. Maka $\mathrm{p}(0.051) \leq \alpha(0.05)$. Dengan demikian diperoleh hasil bahwa faktor dukungan suami memiliki hubungan yang signifikan dengan pemakaian kontrasepsi 
implant pada ibu pasangan usia subur (pus) di Puskesmas Aek Nauli Kec.Siantar Selatan Kota Pematang Siantar tahun 2017.

Tidak adanya diskusi antara suami istri mungkin merupakan cerminan kurangnya minat pribadi, penolakan terhadap suatu persoalan tau sikap tabu dalam membicarakan hal-hal yang berkaitan dengan aspek seksual. Apabila pasangan suami istri mempunyai sikap positif terhadap $\mathrm{KB}$, maka mereka cenderung akan memakai kontrasepsi. Tidak hanya diskusi tentang alat $\mathrm{KB}$ yang dipakai oleh istri dapat menjadi halangan pemakaian kontrasepsi.

Penelitian ini sejalan dengan penelitian yang dilakukan Suyanti yang berjudul diterminan penggunaan alat kontrasepsi implant di wilayah kerja UPTD Puskesmas SukaHaji Kabupaten Majalengka Tahun 2015 hasil uji chi-square diperoleh $\mathrm{p}$ value $=0.002$ atau $\mathrm{p}$ value < 0.05, dengan demikian dapat disimpulkan ada hubungan yang signifikan antara dukungan suami dengan pemakaian kontrasepsi implant. $^{20}$

Menurut asumsi peneliti, darihasilpenelitianmayoritasrespondentidakmen dapatdukungandarisuamidalampemakaiankontr asepsi implant namuntetapmenggunakan implant sebagaikontrasepsi. Dukungan suami sangatlah diperlukan ibu tapi pada kenyataannya banyak suami yang tidak perduli dan merasa kontrasepsi bukanlah tanggung jawabnya oleh sebab itu meskipun tidak mendapat dukungan suami namun ibu tetap menggunakan kontrasepsi implant disebabkan oleh beberapa kemungkinan, seperti pengetahuan ibu tentang implant dan paritas ibu yang sudah banyak.

\section{KESIMPULAN}

Dari hasil analisis bivariat yang menggunakan uji statistik chi-square diperoleh hasil faktor yang berhubungan dengan pemakaian kontrasepsi implant di PuskesmasAek Nauli Kec.Siantar Selatan Kota Pematang Siantar tahun 2017 yaitu faktor pendidikan $\quad(p=0.017<\alpha=0.005), \quad$ faktor pengetahuan $\quad(p=0.014<\alpha 0.05)$ dan faktor dukungan suami $(\mathrm{p}=0.05 \leq \alpha=0.005)$

\section{SARAN}

Bagi ibu pasangan usia subur (PUS) diharapkan menggunakan kontrasepsi yang aman dan efektif mencegah dari kehamilan yang tidak diingin, salah satunya yaitu menggunakan kontrasepsi jangka panjang implant yang lebih praktis dan efektif digunakan ibu. Agar kelahiran anak dapat terencana dan persiapan masa depan yang lebih baik akan terjamin baik.

\section{KEPUSTAKAAN}

1. Dr. Lucky Tufik, Kurniawan. Buku Ajar Kependudukan Dan Pelayanan KB, Jakarta : Buku Kedokteran. EGC ; 2016

2. Yetti Anggraini, Martini. Pelayanan Keluarga Berencana. Yogyakarta : Rohima Press ; 2016

3. Suratu, dkk. Pelayanan Keluarga Berencana dan Pelayanan Kontrasepsi, Jakarta : Trans Infomedia ; 2016

4. Dyah Noviawaty Setya Arum, Panduan Lengkap Pelayanan KB Terkini, Yogyakarta : Nuha Medika ; 2016

5. Nurcahaya, syafneli hsb. Faktor faktor Yang Berhubungan Dengan Rendahnya Minat Ibu Dalam Menggunakan KB Implant Di Desa Tali Kumain Wilayah Kerja Puskesmas Tambusai Kabupaten Rokan Hulu Tahun 2014

6. Bathara musu' Appriana, Faktor faktor yang berhubungan dengan pemakaian kontrasepsi implant pada akseptor $\mathrm{kb}$ di puskesmas ciomas kecamatan ciomas kabupaten Bogor tahun 2012.

7. Data dan Informasi Kesehatan dan Profil Kesehatan Indonesia.Kementrian Kesehatan Indonesia, 2016

8. BKKBN Sumatra Utara, 2016

9. Badan Pusat Statistik Kota Pematang Siantar, 2015

10. Mehartati, tuti. Faktor - Faktor Yang Berhubungan Dengan Pemilihan Alat Kontrasepsi Implant Di Wilayah Kerja Puskesmas Darul Azhar Kabupaten Tanah Bumbu Tahun 2013

11. Prastikaningrum, Anistika, arus dkk. Faktor - faktor Yang Berhubungan Dengan Pemilihan Alat Kontrasepsi Implant Pada Akseptor KB Aktif Di BPM Jarmini Desa Leyangan Ungaran Tahun 2014

12. Nurcahaya, syafneli hsb. Faktor faktor Yang Berhubungan Dengan Rendahnya Minat Ibu Dalam Menggunakan KB Implant Di Desa Tali Kumain Wilayah Kerja Puskesmas 
Tambusai Kabupaten Rokan Hulu Tahun 2014

13. Sri, Handayani, Buku Ajar Pelayanan Keluarga Berencana, Yogyakarta : Pustaka Rihana ; 2016

14. Niken, Meilani, Pelayanan Keluarga Berencana (Dilengkapi Dengan Penuntun Belajar) Yogyakarta : Fitramaya ; 2016

15. Notoadmodjo, soekidjo, Metrodologi Penelitian Kesehatan, Jakarta : Rineka Cipta ;2016

16. Muhammad, Imam, Panduan Penyusunan Karya Tulis Ilmiah Bidang Kesehatan Menggunakan Metode Penelitian, Bandung : Cita Pustaka Media Perintis ; 2016

17. Sudigdo, sastroasmoro, Dasar - dasar Metodologi Penelitian Klinis, Jakarta : Sagung Seto ; 2016

18. Muhammad, Imam, Pemanfaatan SPSS Dalam Penelitian Bidang Kesehatan Dan Umum, Bandung : Cita Pustaka Media Perintis ; 2016

19. Putri, rahma, Beberapa Faktor yang berhubungan Dengan Pemakaian Metode Kontrasepsi Implant Di Desa Jimbaran Kecamatan Bandungan Kabupaten Semarang Tahun 2014.

20. Suyanti, Determinan Penggunaan Alat Kontrasepsi Implant Di Wilayah Kerja UPTD Puskesmas SukaHaji Kabupaten Majalengka Tahun 2015. 